\title{
ARTIKELEN
}

\section{Nieuwe hindoetempels in Nederland: een schets van lokale initiatieven en gemeentelijke reacties}

\author{
Freek L. Bakker
}

\begin{abstract}
Op dit moment, het voorjaar van 2019, zijn er in Nederland 44 hindoetempels. De meeste daarvan zijn gevestigd in voormalige winkels, garages, schoolgebouwen of andere locaties die oorspronkelijk niet bedoeld waren voor een hindoeïstisch heiligdom. ${ }^{1}$ Dit artikel analyseert de reacties van de lokale overheid in verschillende Nederlandse gemeenten wanneer hindoes met plannen kwamen voor een nieuwe tempel. Daarbij gaat de aandacht uit naar de rol van de verschillende actoren in dit proces, zoals de opdrachtgevers, de architect, de gemeenteraad, de gemeentelijke ambtenaren en de welstandscommissie. Het samenspel tussen deze actoren blijkt in elke gemeente steeds weer anders.

Daarbij mag niet vergeten worden dat niet alleen de hindoes door dit proces heen gingen. De moslims die in Nederland wonen zijn ook door dergelijke processen heen gegaan. Daarover is al sinds het begin van de jaren negentig van de vorige eeuw veel gepubliceerd. ${ }^{2}$ Een deel van de bevindingen in dit artikel komen overeen met die in de uit 2009 daterende proefschriften van Marcel Maussen en Eric Roose.
\end{abstract}

\section{Een korte geschiedenis}

De schattingen over het aantal hindoes in Nederland lopen nogal uiteen. Op basis van een schatting van het Centraal Bureau voor de Statistiek uit 2004 en gegevens bijeengebracht uit andere bronnen kwam ik halverwege 2018 tot een aantal van $120.000 .^{3}$ Inmiddels is duidelijk geworden dat er zo'n 50.000 Indiase kenniswerkers in Nederland zijn gekomen. Waarschijnlijk is $80 \%$ van hen eveneens hindoe. Vandaar dat ik voor dit artikel uitga van ongeveer 160.000 hindoes in ons land.

1 F.L. Bakker, Hindus in the Netherlands, Berlijn e.a.: LIT-Verlag 2018, p. 173. Na de voltooiing van dit boek heb ik geconstateerd dat er nog een tempel was in Zoetermeer in een voormalig jeugdcentrum. Verder is er in die tussentijd nog een nieuwbouwtempel voltooid en geopend in Almere. Vandaar dat in mijn boek gesproken wordt over 42 tempels en in dit artikel over 44 .

2 Zie bijv. M. Maussen, 'Scheiding van kerk en staat en de islam op gemeentelijk niveau', Justitiële verkenningen 2007, p. 20-36; M. Mausen, Constructing Mosques: The Governance of Islam in France and the Netherlands, Amsterdam: Amsterdam School for Social Science Research 2009; E. Roose, The Architectural Representation of Islam: Muslim Commissioned Mosque Design in the Netherlands, Amsterdam: Amsterdam University Press 2009. Bakker 2018, p. 16-18. 
De Hare Krishna's richtten in Nederland de eerste hindoetempel in die openstond voor bezoekers van buiten. Veel hindoes hebben in huis een eigen privétempel, waar ze dikwijls dagelijks 's morgens of 's avonds een püjā of eredienst verrichten waarin zij kleine offergaven aanbieden en meestal ook een tijdje mediteren. Maar in juli 1972, voorafgaand aan een bezoek aan Amsterdam van de leider van hun beweging, Shrila Prabhupada (1896-1977), openden de Hare Krishna's een tempel in een garage in de Bethaniënstraat in Amsterdam. In 1974 hadden zij deze plek alweer verlaten. ${ }^{4}$ Niet lang daarna werden ook andere bedehuizen geopend, de meeste door de hindostanen ${ }^{5}$ die in deze jaren in groten getale vanuit Suriname naar Nederland verhuisden. Toch lieten ook andere, veelal autochtone, hindoes zich niet onbetuigd, bijvoorbeeld de aanhangers van verschillende Indiase goeroes, van wie Sathya Sai Baba (1926-2011) en Bhagwan Shree Rajneesh (1931-1990) de belangrijkste waren. In de jaren tachtig van de vorige eeuw vluchtten zo'n drieduizend Tamils uit Sri Lanka naar Nederland. Ook zij begonnen tempels in te richten.

In 1990 werd de eerste nieuwbouwtempel gebouwd, de Radha Krishna Mandir in Lelystad. Het was een houten keet, die helaas al in 1995 in vlammen opging. Of de brand was aangestoken of niet is nooit helemaal duidelijk geworden. De opdrachtgevers voor dit bedehuis waren hindostanen met een Surinaamse achtergrond. ${ }^{6}$

In maart 2000 werd weer een nieuwbouwtempel gebouwd. Deze Radha Krishna Mandir aan de Saaftingestraat in Amsterdam was van steen. Ook hier waren Surinaamse hindostanen de initiatiefnemers. ${ }^{7}$ Een groep Tamils uit Sri Lanka opende op 6 juli 2003 een tempel in een buitenwijk in het zuiden van Den Helder. Wat aanvankelijk niet meer dan een loods met een fraaie ingang was, ontpopte zich tot een stijlvolle Nederlandse versie van de Zuid-Indiase Tamiltempel toen in september 2013 de zogenoemde gopura, de tempeltoren, werd ingewijd. ${ }^{8}$ Op 18 december 2005 vond de officiële opening plaats van de Shree Raam Mandir in Wijchen. Ook dit gebouw werd neergezet in opdracht van Surinaamse hindostanen. ${ }^{9}$ Op 2 juli 2012 werd een volgende nieuwbouwtempel ingewijd, de Sada Shiva Dham op een ashram in Loenen in de omgeving van Apeldoorn. De

4 Bakker 2018, p. 50-53; R. Kranenborg, Neohindoeïstische bewegingen in Nederland: Een encyclopedisch overzicht (serie Wegwijs Wereldreligies), Kampen: Kok 2002, p. 152-158, 246.

5 De officiële Nederlandse spelling van dit woord is Hindoestanen, met een hoofdletter. Omdat dit de suggestie wekt dat zij allen hindoe zijn, gebruiken de hindostanen zelf zowel in Suriname als in Nederland liever het woord hindostanen. Een groot aantal van hen is immers moslim, terwijl er ook een klein aantal christen is. De hoofdletter laat ik vallen, omdat creolen met een kleine letter geschreven wordt. De hoofdletter suggereert ten onrechte dat de hindostanen superieur zouden zijn.

6 Bakker 2018, p. 13; J.P. Schouten, 'Nieuwe wegwijzer in hindoeïstisch Nederland', Religieuze bewegingen in Nederland 1991, p. 56-57.

$7 \quad$ Bakker 2018, p. 122-126.

8 Bakker 2018, p. 129-135. Hier ben ik zelf bij aanwezig geweest.

9 L. Albers, Hindoeïsme bij de Shree Raam Mandir te Wijchen (bachelorsscriptie), Utrecht: Universiteit Utrecht 2009, p. 19-20; Bakker 2018, p. 144-147; A. Nugteren, 'Home is Where the Murtis Are: A Hindustani Community and Its Temple in Wijchen, the Netherlands', Journal of Religion in Europe 2009, 2, p. 123-124. 
opdrachtgevers voor de bouw van dit heiligdom behoorden tot een groep autochtone Nederlanders die de goeroe Babaji vereren. ${ }^{10} \mathrm{Na}$ de voltooiing van dit bedehuis zijn er in Nederland nog twee andere nieuwbouwtempels geopend, de Dew Mandir in Den Haag (op 28 mei 2017) en de Shri Vishnu Mandir in Almere (op 27 april 2018). Inmiddels staan er zes hindoeïstische nieuwbouwtempels in Nederland.

In deze verhandeling komt de vraag aan bod hoe de lokale overheid reageerde op plannen van hindoes om een tempel binnen hun gemeente te bouwen en hoe zij daarmee mede vormgaven aan de vrijheid van godsdienst in dit land. Wie een tempel gaat bouwen, krijgt te maken met bestemmingsplannen en die worden door de overheid vastgesteld. Het zal zelden voorkomen dat zo'n bestemmingsplan al op voorhand rekening heeft gehouden met de komst van een religieus gebouw, laat staan met de komst van een hindoetempel.

Ik richt mij op de gang van zaken rond de volgende vier tempels: de Radha Krishna Mandir in Amsterdam, de Sri Varatharajah Selvavinayagar Kovil in Den Helder, de Shree Raam Mandir in Wijchen en de Sada Shiva Dham in Loenen. Het onderzoeksmateriaal voor deze analyse is voornamelijk afkomstig uit interviews.

\section{De Radha Krishna Mandir in Amsterdam}

Sinds 1984 kwam een groep Surinaams hindostaanse hindoes met een traditioneel orthodoxe inslag bijeen in een gebouw dat als tempel was ingericht, maar op de nominatie stond gesloopt te worden. In 1997 was het zover. De mürti's, zoals de beelden van de godheden worden genoemd, werden naar buiten gebracht en opgeslagen. Men ging op zoek naar een alternatieve locatie. Daartoe deed men ook een beroep op de gemeente. Maar de gemeente wilde geen locatie aanbieden. De gelovigen moesten zelf op zoek. De motivatie voor de weigering van de gemeente was dat zij geen recht heeft een keuze te maken voor een bepaalde religieuze stroming. Daarmee bedoelde de gemeente dat zij niet voor de ene groep wel een plek kan gaan zoeken en voor de andere niet. Daarnaast werd de Indiase ambassade om financiële ondersteuning gevraagd, maar ook die gaf niet thuis.

Een hindostaanse hindoe, dr. Bissessar, die gemeenteambtenaar was en lid van het Christen Democratisch Appel (CDA), bood uitkomst. Hij bracht het bestuur van deze groep, de Stichting Shri Sanatan Dharm Amsterdam (SSDA), in contact met de stadsdeelraad van Osdorp. De stichting kreeg een stuk grond van $400 \mathrm{~m} 2$ in erfpacht toegewezen. Hoewel het CDA in Amsterdam in die tijd niet zoveel invloed had als de landelijke partij, was het niet onbelangrijk. Het perceel lag naast een terrein dat bestemd was voor de bouw van een moskee. Hoewel de opvattingen van veel hindostaanse hindoes over Turkse en Marokkaanse moslims niet zo positief zijn, verklaarde een vooraanstaand lid van de SSDA dat zij nooit problemen hebben gehad met de moslims van de naburige moskee. ${ }^{11}$

11 Mevrouw R. Doergaram Tewarie, een vooraanstaand lid van deze tempelgemeenschap, in een interview op 23 maart 2016. 
Via paṇdit R. Ramsoekh, die in die tijd voorzitter was van de SSDA, kwam het bestuur in contact met de hindostaanse architect Sunil Thakoer. Tijdens een van de eerste gesprekken vroeg Thakoer aan het bestuur wat voor tempel zij wilden. Ze zeiden dat de tempel in Neasden in Londen hun voorbeeld was. De architect legde uit dat zo'n tempel erg duur was en dat het terrein dat zij gekregen hadden daarvoor te klein was. Daarop besloten zij om een klein rechttoe rechtaan gebouw voor te stellen dat $f 80.000$ zou gaan kosten. Dat voorstel werd door de welstandscommissie afgekeurd. De commissie was van mening dat het bestuur met een nieuw voorstel moest komen voor een grotere en mooiere tempel. Maar het was niet de bedoeling dat die tempel zo zou domineren dat het zorgcentrum dat erachter stond in het niet zou verdwijnen. Vervolgens kwam Thakoer met een tekening die alleen de huidige tempelzaal met de drie torens behelsde. Dat plan kon wel de goedkeuring van de welstandscommissie wegdragen. Later werd hier nog wel een uitbreiding aan de zijkant van het gebouw aan toegevoegd. Dit voorstel behelsde in principe al de Indiase sikhara-torens die er pas in 2015 op werden gezet en de koepel die er in juni 2017 op geplaatst werd. Dit plan zou wel $f 900.000$ kosten. De kosten van het meubilair en de inrichting waren echter niet in dit bedrag inbegrepen. Uiteindelijk heeft de bouw van dit bedehuis volgens de website van de tempel $€ 650.000$ gekost. Dit bedrag werd in gedeelten bij elkaar verzameld. Daarom kwamen de śikhara-torens en de koepel pas later op het tempelgebouw. Op 19 juli 1999 begon men met de bouw. De drie torens aan de voorgevel herinneren duidelijk aan het Surinaamse model voor een hindoetempel, terwijl de koepel boven de mürti's gebruikelijk is bij de hindoebedehuizen in Trinidad. Dit betekent dat architect Thakoer een nieuwe ontwikkeling begonnen is, die inderdaad in Nederland later navolging heeft gekregen, bijvoorbeeld bij de Shri Vishnu Mandir in Almere.

Op dit moment heeft het tempelbestuur nog steeds goed contact met de gemeente en met verschillende scholen in Amsterdam. Meer dan eens komen groepen leerlingen langs om in de tempel te worden voorgelicht over het gedachtegoed, de rituelen en de levensstijl van het Surinaams hindostaanse hindoeïsme. ${ }^{12}$ In het voorafgaande werd duidelijk dat de gemeentelijke overheid op drie manieren betrokken is geweest bij deze initiatieven. In eerste instantie weigerde de gemeente om een locatie aan te bieden aan de initiatiefnemers met als argument dat de lokale overheid niet één bepaalde religieuze stroming kon ondersteunen bij de zoektocht naar een nieuw gebedshuis. Men beriep zich op de neutraliteit van de overheid op dit punt.

Toch kwam er, na wat onderhandelen met een hindostaanse gemeenteambtenaar die hindoe is en als lid van het CDA religie een goed hart toedraagt, beweging in de zaak en werd de stichting na contact met de deelgemeente Osdorp een stuk

12 Bakker 2018, p. 121-129. Veel informatie is te danken aan voor een deel telefonische interviews met architect Sunil Thakoer op 31 maart 2016, mevrouw R. Doergaram Tewarie, een vooraanstaand lid van deze tempelgemeenschap op 23 maart 2016, Sieuwdath Sardjoe, penningmeester van het tempelbestuur op 4 november 2014 en 14 februari 2016, en e-mails gedateerd op 27 maart 2017 en 30 januari 2018 van pandit Haridatt Koendan, die regelmatig in deze tempel voorgaat. Zie ook de website: Radha Krishna Mandir Amsterdam, www.radhakrishnamandir.nl, geraadpleegd op 1 oktober 2013. 
grond aangeboden in een nieuw te bouwen buurt in Slotervaart. Hier was al een moskee gepland. Daarom is het heel goed mogelijk dat men dacht dat er ook nog wel een hindoe-mandir bij kon.

Maar toen de groep hindoes met een eerste voorstel kwam, werd dat direct door de welstandscommissie afgewezen omdat het te weinig ambitieus was. Daarmee dwong de gemeente in feite de hindoes om dieper in hun portemonnee te tasten.

\section{De Sri Varatharajah Selvavinayagar Kovil in Den Helder}

In de loop van de jaren tachtig van de vorige eeuw kwam een groep Tamil-vluchtelingen uit Sri Lanka terecht in het noorden van Noord-Holland. Op 29 maart 1991 vormde een aantal van hen een vereniging waaruit later de Sri Varatharajah Selvavinayagar Kovil zou ontstaan. Ze begonnen met bijeenkomsten in de pastorie van de toenmalige rooms-katholieke St. Nicolaaskerk in Den Helder. Op 11 september 1992 verhuisden ze naar een voormalig schoolgebouw aan de Elzenstraat 36. Op 1 september 2000 kochten zij een stuk grond aan de Annie Romein-Verschoorlaan 31, en op 22 augustus 2001 begon de bouw van de tempel. ${ }^{13}$ Duco Kapitein was de architect en tekende het casco en de draagconstructie van de tempel. De rest werd gedaan door een kaste van zogenoemde sthapati's in India. Zij bouwden op basis van deze draagconstructie en het casco een tempel die zo veel mogelijk moest voldoen aan de regels die daarvoor bestaan in de traditie van de Zuid-Indiase Tamil-hindoes. Hoe streng deze sthapati's daarin waren, bleek uit het feit dat de tempel absoluut op de oost-westlijn moest staan, ook al betekende dat een afwijking van de straatrichting. De andere gebouwen in deze wijk staan loodrecht op de straatrichting, de Tamil-tempel niet. Kapiteins taak was ervoor te zorgen dat het overleg met de gemeente goed verliep en dat het gebouw beantwoordde aan de eisen van het Nederlandse klimaat en de bepalingen en wetten van de Nederlandse overheid. Verder bemiddelde hij bij het verkrijgen van werkvergunningen voor de sthapati's uit India.

De welstandscommissie heeft zich volgens Kapitein 'zeer neutraal' gedragen. Men keek alleen of het kon en of het niet in strijd was met het bestemmingsplan, en men verleende verder alle medewerking. Maar men had te maken met Tamil-hindoes die ten aanzien van hun tempel de opstelling hadden van 'zo wordt het en anders kan het niet'. Er was dus nauwelijks onderhandelingsruimte.

In een interview vertelde de architect ook dat het areaal waar de tempel gebouwd zou worden oorspronkelijk was bedoeld voor gemengde bebouwing en stedelijke functies; er zouden huizen komen, maar ook werkplaatsen voor kleine bedrijven. Het uitvaartcentrum was de eerste. Maar na de bouw van dit centrum heeft de gemeente het areaal bestemd voor religieuze gebouwen voor gelovigen van uiteenlopende achtergrond. Het is op die manier een soort 'reli-areaal' geworden, met behalve de tempel een moskee en kerken van zeer uiteenlopende signatuur

13 Telefonische interviews met de toenmalige katholieke pastor, Nico H.A. de Gooijer, op 2 oktober 2017, en de voorzitter van het tempelbestuur, Gunanayagam Manoraahawan, op 7 juli 2015 en 13 april 2017. Bakker 2018, p. 129-130; Vereniging Sri Varatharaja Selvavinayagar, Sri Varatharaja Selvavinayagar Kovil, Den Helder: Vereniging Sri Varatharaja Selvavinayagar 2013. 
met een over het algemeen niet zo grote aanhang in Nederland. Zoals je in veel gemeenten een industrieterrein hebt, heb je in Den Helder ook een 'reli-terrein'. ${ }^{14}$ De gemeente Den Helder gaf hindoes dus de ruimte om een tempel te realiseren, maar deze werd wel gebouwd in een uithoek van de stedelijke agglomeratie. Het is mogelijk typerend voor de ruimte die de gemeente wil bieden voor gebouwen van mensen met een religie afwijkend van de Nederlandse godsdienstige mainstream.

\section{De Shree Raam Mandir in Wijchen}

In 1975 kwam een groep hindostaanse families in Wijchen en Boxmeer terecht omdat een van de moeders voor medische behandeling regelmatig in het academisch ziekenhuis in Nijmegen moest zijn. De groep kwam elke zondag bijeen in een woning van een van de families om daar een hindoeïstische plechtigheid bij te wonen. In 1989 ontstond uit deze groep de Stichting Jai Hanuman om de plechtigheden beter te organiseren en de financiën goed te regelen. 'You must be the change you wish to see in the world' was het motto van de stichting. Daarmee wilde de organisatie laten zien dat zij een bijdrage wilde leveren aan de multiculturele samenleving en op die manier paste zij goed binnen het beleid van de overheid en ontving zij van de lokale overheid financiële ondersteuning. In werkelijkheid waren de activiteiten van de stichting vooral gericht op de eigen groep. ${ }^{15}$ In 1998 ging de organisatie op zoek naar ruimte in een ander gebouw. De gemeente Wijchen bood hun een ruimte aan in een zaal van buurtcentrum Het Molenhuis. Maar binnen de groep wilden verschillende personen liever een eigen gebouw laten bouwen, waarin plaats zou zijn voor het uitvoeren van de hindoeïstische rituelen en voor het organiseren van feesten, lezingen, lessen Hindi en Indiaas koken en andere cursussen, en voor een winkel en een vegetarisch restaurant. Ook wilde men van het gebouw een centrum voor interreligieuze dialoog maken. Men verwachtte dat de gemeente bereid zou zijn subsidie te geven voor een multicultureel centrum en dat de hindoes bereid zouden zijn giften te geven voor een echte hindoe-mandir. In 2002 trad de Partij van de Arbeid-politicus G.A.W. Noordewier aan als burgemeester en dat bracht de zaken in een stroomversnelling. Jaipalsingh Lalbahadoersing, die later de belangrijkste priester van de tempel zou worden, legde contact met hem en Noordewier beloofde zijn best voor hen te zullen doen. Als gevolg daarvan ging ook een van de wethouders zich voor hen inzetten.

Eerst werd gezocht naar een stuk grond. Ondertussen had Jaipalsingh Lalbahadoersing zich voorgenomen om elk stuk grond te aanvaarden. Er waren in Wij-

14 Telefonisch interview met architect Duco Kapitein op 14 april 2017, en de voorzitter van het tempelbestuur, Gunanayagam Manoraahawan, op 7 juli 2015 en 13 april 2017. Dit werd bevestigd in een e-mail gedateerd op 25 april 2018 en verzonden door gemeenteambtenaar A.J. den Braber-Bossche van de gemeente Den Helder.

15 L.M.H. Bloemberg, Tussen traditie en verandering: Hindostaanse zelforganisaties in Nederland, Utrecht/Amsterdam: Koninklijk Nederlands Aardrijkskundig Genootschap/Instituut voor Sociale Geografie, faculteit Ruimtelijke Wetenschappen Universiteit van Amsterdam 1995, p. 155, 159-160; Albers 2009, p. 17-19. 
chen drie kleine kavels. Lalbahadoersing koos voor het perceel vlak bij het spoor. $\mathrm{Na}$ een kleine herverkaveling was de vorm groot genoeg om daar een mandir op te bouwen. ${ }^{16}$

Architect Jay Tetar werd gevraagd een ontwerp te maken. Hij tekende een gebouw met een zadeldak dat duidelijk een tempel voorstelde. Tetar, die aanwezig was bij de bijeenkomst van de gemeentelijke welstandscommissie, meldde dat dit ontwerp binnen vijf minuten door de welstandscommissie was afgewezen. ${ }^{17}$ De commissie wilde een ontwerp dat meer op een kantoorgebouw zou lijken, want dat zou beter in de omgeving passen. Daarbij vond de welstandscommissie dat als zou blijken dat er te weinig animo voor de tempel was, het gebouw als kantoorgebouw moest kunnen dienen. Aan het begin van de 21ste eeuw was er in Nederland een schreeuwend tekort aan kantoorruimte. Daarbij werd de eis gesteld dat de ingang aan de kant van de Stationslaan moest komen, want het gebouw zou een nummer krijgen aan de Stationslaan. De welstandscommissie stelde geen speciale veiligheidseisen.

Dit alles leidde tot nieuwe bezinning in de bouwcommissie. Tetar stelde toen voor de aandacht niet te richten op esthetiek, maar op de activiteiten die in het gebouw zouden plaatsvinden. Dat leidde tot een rechthoekig gebouw zonder de uitstraling van een kerk.

De lotusvorm in de ramen was nog wel afkomstig uit het eerste ontwerp. Het was de bedoeling die vorm te accentueren door er een houtwerk voor te plaatsen in een andere kleur. Maar dat werd niet toegestaan, want dat vond de welstandscommissie te provocerend. Verder besloot de gemeente geen subsidie voor de bouw te geven. De gedachte dat de gemeente een multifunctioneel centrum wel zou steunen, bleek niet op waarheid te berusten. ${ }^{18}$

Op 18 december 2005 verrichtte de burgemeester de officiële opening en op 15-19 januari 2006 vonden de plechtigheden plaats waarin de mürti's werden gewijd.

Het gebouw heeft drie verdiepingen. De tempelzaal is ingericht op de bovenste verdieping. De eerste verdieping heeft een grote zaal met enkele kleinere zalen. Daar kunnen congressen, feesten en maaltijden worden gehouden. Op de begane grond bevinden zich de winkel en het vegetarisch restaurant.

Er was geen geld meer om de Noord-Indiase koepels op het dak te bouwen. ${ }^{19}$ Daarom oogt het gebouw als een blokkendoos, meer een kantoorgebouw dan een hindoetempel. Alleen de ramen van de bovenverdieping hebben iets religieus. Inderdaad is in het raamwerk een lotus te herkennen, maar ze doen ook denken aan de kerkramen van een christelijke kerk.

In dit geval had de lokale overheid via de welstandscommissie veel invloed op het uiterlijk en op de indeling van het gebouw. Inderdaad wordt de eerste verdieping tegenwoordig van tijd tot tijd ook verhuurd aan activiteiten gericht op kantoor-

16 Interview met Jaipalsingh Lalbahadoersing, een van de initiatiefnemers tot de bouw van de tempel op 7 februari 2017 en telefonisch op 14 juni 2017.

17 Telefonisch interview met architect Jay Tetar op 13 april 2017.

18 Telefonisch interview met architect Jay Tetar op 13 april 2017, aangevuld met informatie uit het interview met Jaipalsingh Lalbahadoersing op 7 februari 2017.

19 Telefonisch interview met Jay Tetar, 13 april 2017. 
werkers. Het lijkt erop dat de Tamil-hindoes door hun harde opstelling een heiligdom konden neerzetten dat niet alleen voor een buitenstaander, maar ook voor hindoes zelf duidelijk herkenbaar is als een hindoeïstische tempel zoals die te vinden is in Zuid-India en Sri Lanka. De hindostanen van Wijchen daarentegen waren bereid tot concessies en eindigden mede daardoor met een 'kantoorgebouw'. Het kan een rol gespeeld hebben dat het model voor een Caraïbische hindoetempel niet zo vast omschreven is als dat van een Zuid-Indiase Tamil-tempel. Maar de Amsterdamse mandir, waarover eerder in dit artikel is geschreven en die ook van hindostaanse hindoes is, is wel duidelijk een hindoetempel waarin ook de Caraïbische achtergrond zichtbaar is.

\section{De Sada Shiva Dham in Loenen}

In 1992 vormde een groep autochtone Nederlandse hindoes die de goeroe Babaji vereerden, de Stichting Haidakhandi Samaj. Deze stichting kocht een landgoed in Loenen, een dorp in de omgeving van Apeldoorn. Op dat landgoed stonden drie aaneengekoppelde houten woningen. Daar begonnen zij een ashram. Maar op Koninginnedag 1994 gingen deze woningen in vlammen op. De stichting besloot een nieuwe ashram en tempel te bouwen. Daartoe moest het bestemmingsplan van de gemeente Apeldoorn, waar ook Loenen onder valt, worden veranderd. Maar de gemeenteraad van Apeldoorn gaf toestemming voor slechts één gebouw. In 1996 werd dit gebouw, de ashram, voltooid. De tempelzaal was ingericht in een van de grote zalen van dit gebouw. Muniraj, die in die tijd de leiding had van de internationale Babaji-beweging, bleef er echter op aandringen dat er een apart tempelgebouw zou komen. Daarom begon men in 2006 aan een nieuwe poging om bij de gemeenteraad van Apeldoorn een plan voor de bouw van een tempel in te dienen. In 2008 werd dit plan ingediend en nu kreeg de stichting wel toestemming. In vergelijking met de stemming over de plannen midden jaren negentig was de samenstelling van de gemeenteraad inmiddels veranderd. Leefbaar Apeldoorn was met zes zetels in de raad gekomen en deze fractie steunde de plannen.

De welstandscommissie was direct enthousiast over dit plan. Daarom diende de stichting in 2010 een officiële aanvraag in voor de bouw van een tempel. Ondertussen onderhandelde zij met de buren om hen ervan te weerhouden bezwaren in te dienen tegen de bouw van dit bedehuis. Verder probeerden zij de bouw en het onderhoud van de tempel op een zo milieuvriendelijk mogelijke wijze uit te voeren. Daarom werd een warmte-energiepomp aangeschaft voor de verwarming van de gebouwen op het complex. Daarvoor vroegen zij subsidie aan bij de gemeente, die zij ook ontvingen.

Op 2 juli 2012 werd het bedehuis in gebruik genomen. De architect functioneerde in dit proces zuiver en alleen als architect en niet als tussenpersoon. De contacten met de gemeente werden onderhouden door het stichtingsbestuur. De architect moest zich van de opdrachtgevers strikt houden aan het voorschrift van de Babaji-beweging dat de tempel een replica moest zijn van de centrale tempel in Haidakhan in India, zij het dat er vanwege het Nederlandse klimaat enige aanpas- 
singen werden toegestaan. Bovendien werd aan de voorkant van de tempel een zogenoemde kirtan-hal gebouwd, zodat de bezoekers warm en droog de rituelen konden bijwonen. ${ }^{20}$

Ook in deze casus heeft de gemeente invloed gehad op het verloop van het proces van realisatie van de tempel. Het ging niet zozeer om de vormgeving van de tempel, maar om de bereidheid toestemming te geven voor de bouw van een hindoegebedshuis. Veel christenen hebben daar moeite mee, wat partijen met een duidelijk christelijke achterban huiverig maakt om die toestemming daadwerkelijk te verlenen. Een verandering in de samenstelling van de gemeenteraad maakte het gemakkelijker voor hindoes om de tempel toch te realiseren. Bovendien gaf de gemeente bij deze tempel ook enige subsidie in de vorm van een bijdrage in de kosten voor de milieuvriendelijke opzet van de verwarming. Hiermee is dit bedehuis het enige van de vier tempelgebouwen in dit artikel dat subsidie van de overheid ontving. Hier kan ook meespelen dat de opdrachtgevers autochtone Nederlanders waren, die weten hoe de hazen lopen in dit land en daar slim gebruik van maken.

\section{In de richting van een conclusie}

Het is tijd om conclusies te trekken. Maar om dat op een goede en verantwoorde wijze te kunnen doen is het noodzakelijk om eerst nog aan twee andere punten aandacht te schenken.

Het eerste punt is dat bij de bouw van de Shri Vishnu Mandir in Almere de toenmalige burgemeester, Annemarie Jorritsma, had bepaald dat het plaatsen van koepels en andere kenmerkende onderdelen van religieuze gebouwen niet tot een latere datum mocht worden uitgesteld, met als argument dat deze gebouwen van meet af aan herkenbaar moesten zijn als moskee, hindoetempel, boeddhistisch centrum of christelijke kerk. Het gevolg daarvan was dat de Shri Vishnu Mandir al jaren voor de voltooiing van de bouw koepels had. Ook dit is een fraai voorbeeld van hoe ver de bemoeienis van de lokale gemeente gaan kan. Maar het is inderdaad waar dat het aanbrengen van koepels vaak wordt uitgesteld. Dat zagen we bij de Radha Krishna Mandir en de Shree Raam Mandir, en eveneens bij de toren boven de ingang van de tempelhal van de Sri Varatharajah Selvavinayagar Kovil. Het tweede is dat Eric Rooses boek The Architectural Representation of Islam: Muslim Commissioned Mosque Design in the Netherlands duidelijk maakt dat al vanaf de bouw van de eerste moskeeën in Nederland, dus vanaf 1950, de overheid voorwaarden heeft gesteld aan het uiterlijk, de grootte en de ligging van het bede-

20 De informatie voor dit deel van het artikel komt uit een interview met Bhaskaranand (Wil Burgmans), dat op 18 september 2015 werd afgenomen door Anne Cazemier, die een masterscriptie schreef over de hindoe tempels van Wijchen en Loenen. Bhaskaranand is op dit moment een van de leidende figuren in de kring van deze tempel. Ikzelf had een interview met hem op 28 november 2015. Daarnaast komt veel informatie van de website Sada Shiva Dham Babaji Ashram, www.babaji.nl/ashram-sada-shiva-dham/, geraadpleegd op 3 mei 2015. Hierbij moet gezegd worden dat deze informatie nu van de website is afgehaald. Ik heb de informatie destijds echter gedownload. De informatie over de gemeenteraad van Apeldoorn kwam voor een deel uit de interviews met Bhaskaranand, maar ook van de website van de gemeente Apeldoorn. 
huis. Zo moest de eerste in Nederland gebouwde moskee, de Haagse Mobarakmoskee, op een villa lijken, omdat zij gelegen was in een villawijk en geen negatieve invloed op de prijs van de huizen daar mocht hebben. ${ }^{21}$ Marcel Maussen maakte een studie waarin hij het optreden van de Franse overheid ten aanzien van de bouw van moskeeën vergeleek met dat van de Nederlandse overheid ten aanzien van dit onderwerp. Hij constateert dat waar bij de komst van de eerste gastarbeiders en de eerste familieherenigingen de overheid een beleid voerde dat gericht was op integratie, er bij de grondwetsherziening van 1983 een einde werd gemaakt aan de rechtstreekse subsidies van de overheid aan religieuze organisaties vanuit het principe dat de overheid tegenover alle religies en levensovertuigingen een onpartijdige houding aan moest nemen. Bovendien probeerden gemeentelijke beleidsmakers vaak om de bouw van nieuwe moskeeën vooral te bespreken in het licht van praktische zaken als parkeerruimte en de inpassing van de nieuwe gebouwen in de bestaande omgeving. ${ }^{22}$ Het boek van Roose maakt ook duidelijk dat de overheid zich altijd met de moskeeën heeft bemoeid, of er nu sprake was van een beleid gericht op integratie of niet. De Nederlandse overheid en gemeenten hebben zich niet alleen bemoeid met hindoetempels en islamitische moskeeën, maar met alle religieuze gebouwen in het land. Een verschil is echter dat zeker in het verleden christelijke kerkgebouwen wel ingepland stonden in de gemeentelijke bestemmingsplannen.

Vooraleer we verder gaan is het goed vast te stellen dat alle hindoetempels gebouwd zijn in de periode waarin de Nederlandse overheid van mening was dat de religieuze gemeenschappen zelf verantwoordelijk waren voor de financiering van hun gebedshuizen en voor het vinden van een locatie of gebouw. Dat zien we duidelijk weerspiegeld in de uitspraak van de gemeente Amsterdam dat zij de hindoes geen hulp kon bieden bij het vinden van nieuwe ruimte voor hun bedehuis. Desondanks zien we dat zodra de hindoes met een plan komen, de overheid wel degelijk een belangrijke actor wordt. Daarbij zijn de volgende vier factoren van belang.

De eerste factor is de samenstelling van de gemeenteraad. Die bleek met name in Apeldoorn, en daarmee Loenen, cruciaal voor het verlenen van toestemming voor een aparte tempel.

In de andere plaatsen was die samenstelling niet zo bepalend. Daar was de opstelling van de lokale ambtenaren belangrijk. In Amsterdam hielp het dat er een hindostaanse ambtenaar was die bij het indienen van de aanvraag voor de bouw van een bedehuis behulpzaam kon zijn. In Wijchen was het de burgemeester die die rol speelde. Zo komen we bij de tweede factor: iemand die goed op de hoogte is van de gang van zaken binnen het gemeenteapparaat en de indieners bij hun aanvraag verder helpt.

De derde factor is de welstandscommissie. Die vervult een sleutelrol. Twee keer werd een voorstel bijna direct afgewezen. Maar toen men in Apeldoorn zo ver was dat men een aanvraag kon indienen, werd die bijna direct aanvaard. De welstandscommissie kan voorwaarden stellen die de indieners op kosten jagen, zoals 
in Amsterdam, of dwingen hun plan ingrijpend te veranderen, zoals in Wijchen. In beide gevallen was het motief dat het gebouw goed in de omgeving moest passen, iets waarop ook gewezen wordt door Maussen. Niettemin blijft dit een aanvechtbaar argument, omdat hier een element van goede smaak in aanwezig is. Over smaak valt niet te twisten, luidt een Nederlands spreekwoord: dat betekent hier dat het uiterlijk van een bepaald gebouw voor de een wel aanvaardbaar kan zijn, maar voor de ander niet. Mensen hebben nu eenmaal een verschillende smaken.

De vierde factor, ten slotte, is de standvastigheid van de opdrachtgevers. Zowel in Den Helder als in Loenen bleek dat wanneer de opdrachtgevers een helder omlijnd voorstel indienen waarbij zij erop staan dat zij hieraan moeten vasthouden omdat dat door de traditie van hun hindoe-achtergrond wordt vereist, zij uiteindelijk hun zin krijgen en een bedehuis kunnen bouwen zoals zij zich dat al aan het begin voor ogen hadden gesteld. In Wijchen was minder duidelijk wat men wilde bouwen. Dat gaf de welstandscommissie de ruimte ingrijpende wijzigingen te eisen. Natuurlijk is niet bekend wat er in Wijchen gebeurd zou zijn als de opdrachtgevers een meer onbuigzame opstelling hadden gekozen. Maar het is niet uit te sluiten dat zij dan inderdaad een gebouw hadden kunnen neerzetten dat in meer opzichten beantwoordde aan hun program van eisen. In Amsterdam was de situatie anders, omdat daar voor een kundig architect was gekozen die in staat was een authentiek hindoeïstisch gebouw neer te zetten dat beantwoordde aan de eisen van de lokale situatie in het begin van de 21ste eeuw.

Ik wil nog even stilstaan bij de rol van de architect. Waar de opdrachtgevers thuis zijn in de gang van zaken in Nederland, zijn architecten meestal puur bezig met het ontwerpen van het gebouw en de dingen daaromheen; zie wat er gebeurd is in Loenen. Waar de opdrachtgevers minder op de hoogte zijn, hebben architecten ook een bemiddelende rol in de contacten met de overheid; zie met name wat is gebeurd in Den Helder.

De studies van Maussen en Roose laten zien dat het overheidsbeleid ten aanzien van de bouw van nieuwe hindoebedehuizen sterk overeenkomt met dat ten aanzien van nieuwe moskeeën. 